\title{
¿Hombre nuevo y Mujer nueva? Lo femenino y lo masculino en la Nueva Trova Cubana de Silvio Rodríguez y Sara González
}

\section{Lorena Alejandra Valdebenito Carrasco}

Instituto de Música, Universidad Alberto Hurtado, Santiago de Chile, Chile lvaldebe@uahurtado.cl

Recepción: marzo 2020 Aceptación: junio 2020.

\section{Resumen}

Este artículo se propone discutir diferentes aspectos relacionados con la creación musical en la canción de autor/a de dos importantes exponentes de la Nueva Trova Cubana. El marco histórico de la música revolucionaria en la década de 1960 dibuja un ideario de lo femenino que emerge como representación en las canciones de Silvio Rodríguez, y como encarnación en la figura de la trovadora, Sara González. En términos metodológicos revisaremos distintas estrategias de enunciación musical, para una construcción de lo femenino y lo masculino evocada desde los postulados políticos del "Hombre nuevo" (Guevara, 1979), y los puntos de tensión que surgen desde la creación femenina, para enfrentarse a lo que sería la "Mujer nueva" (Kollontái, 2000 [1977]) en el contexto de la Nueva Trova. Los cruces políticos de lo femenino y lo masculino nos permiten aproximarnos a la canción de autor/a como un relato, convertido en un campo de batalla ideológico, que negocia diferentes grados de apropiación de significados. En este sentido nos preguntamos: ¿Qué ideario femenino se construye tanto en la representación como en la creación musical? ¿Cómo se construye la figura de la trovadora cubana en un contexto revolucionario masculino? ¿Qué relevancia tiene Silvio Rodríguez como figura que representa el canon masculino respecto de Sara González? ¿Cuáles son los espacios políticos que se negocian en la construcción del trovador y trovadora en el marco del "Hombre nuevo" y la "Mujer nueva"?

Palabras clave: lo femenino, lo masculino, Hombre nuevo, Mujer nueva, Nueva Trova Cubana 


\title{
New Man and New Woman? The Feminine and the Masculine in the New Cuban Trova of Silvio Rodríguez and Sara González
}

\begin{abstract}
This article proposes to discuss different aspects related to the musical creation in the author's song by two important exponents of the Nueva Trova Cubana. The historical framework of revolutionary music in the 1960s, draws an ideology of the feminine that emerges as a representation in the songs of Silvio Rodríguez, and as an embodiment in the figure of the troubadour: Sara González. In methodological terms we will review different strategies of musical enunciation, for a construction of the feminine and masculine evoked from the political postulates of the "New man" (Guevara, 1979), and the points of tension that arise from the feminine creation, to face what would be the "New woman" (Kollontái, 2000 [1977]) in the context of the Nueva Trova. The political crosses of the feminine and the masculine, allow us to approach the author's song as a story, turned into an ideological battlefield, which negotiates different degrees of appropriation of meanings. In this sense we ask ourselves: What feminine ideology is constructed both in the representation and in the musical creation? How is the figure of the Cuban troubadour built in a male revolutionary context? What relevance does Silvio Rodríguez have as an actor representing the male canon regarding Sara González? What are the political spaces that are negotiated in the construction of the troubadour and woman troubadour within the framework of the "New man" and the "New woman"?
\end{abstract}

Keywords: The feminine, the masculine, New man, New woman, Nueva Trova Cubana

\section{Novo homem e Nova mulher? 0 feminino e o masculino na Nova Trova Cubana de Silvio Rodríguez e Sara González}

\section{Resumo}

Este artigo propõe discutir diferentes aspectos relacionados com a criação musical na canção do autor de dois importantes expoentes da Nova Trova Cubana. 0 quadro histórico da música revolucionária na década de 1960, desenha uma ideologia do feminino que surge como uma representação nas canções de Silvio Rodríguez e como uma encarnação na figura do trovadora: Sara González. Em termos metodológicos, faremos a revisão 
de diferentes estratégias de enunciação musical, para uma construção do feminino e do masculino evocada a partir dos postulados políticos do "Novo homem" (Guevara, 1979), e os pontos de tensão que surge da criação feminina para enfrentar o que seria a "Nova mulher" (Kollontái, 2000 [1977]) no contexto da Nova Trova. As cruzes políticas do feminino e do masculino permitem-nos abordar o canto do autor como uma história, transformada num campo de batalha ideológico, que negoceia diferentes graus de apropriação de significados. Neste sentido, perguntamo-nos: que ideologia feminina é construída tanto na representação quanto na criação musical? Como é a figura do trovador cubano construída em um contexto revolucionário masculino? Que relevância tem Silvio Rodríguez como figura do canon masculino em relação a Sara González? Quais são os espaços políticos que são negociados na construção do trovador e da trovadora no âmbito do "Novo homem" e da "Nova mulher"?

Palavras-chave: o feminino, o masculino, Novo homem, Nova mulher, o Nova Trova Cubana

\section{Ideario de lo femenino en Silvio Rodríguez: un gesto de evocación caleidoscópica}

La mujer, como objeto de estetización en el arte, es una práctica que ha ido configurando cánones de idealización. Estos cánones, basados en estereotipos "se hacen plenamente entendibles a la luz del estudio del proceso histórico que ha seguido el discurso masculino sobre el cuerpo, la psicología y la imagen de lo femenino" (Alario, 1995, p. 45).

Habitualmente, cuando los sujetos masculinos refieren a lo femenino desde una perspectiva afectiva heterosexual en la dinámica de lo imaginado, esta categoría se despliega desde la evocación amorosa/erótica/sexual/sensual/virginal, entre otras posibilidades, cuyo factor común es la aparición de un sujeto femenino corporeizado. ${ }^{1}$ Ello ocurre ya sea en un ideario de lo femenino desde las artes de los ojos: como la pintura, la escultura, el teatro, el cine, como también desde el arte del cuerpo, como la danza, el ballet. 0 , desde el arte de los oídos: como la poesía o la música. Juega un papel fundamental, en este último caso, la creación de la música a partir de lo femenino imaginado en la categoría mujer -lo que se conoce como musa inspiradora- como también del contenido de la música misma, cuando está dedicada a una mujer.

${ }^{1}$ Diferentes trabajos critican los idearios femeninos en el arte, cf. Caballero (2002), Ramos (1989) y Perrot (1989). 
Nos interesa aproximarnos al modo en que Silvio Rodríguez dialoga con la categoría de lo femenino, desde la escucha del registro (pista), como lugar medial en la voz del trovador. El ideario que Rodríguez dibuja sobre $l o$ femenino, para una configuración de la mujer como sujeto desde un decir subjetivo, es lo que nos parece relevante de revisar.

Silvio Rodríguez como "persona” en el sentido de Moore (2012, p. 179), produce una voz que expresa un decir poético dedicado a la mujer (desde un espacio imaginado). Al mismo tiempo que Rodríguez es ontológicamente una persona en la pista que escuchamos, a su vez, visibiliza desde su voz a otra persona, la mujer. En este sentido, la mujer y su carácter femenino es construido por el trovador como un personaje mediado por el tamiz de género, lo político y lo ideológico en un contexto histórico. Cabe señalar que en los años 60 y 70 se le otorga importancia a la autenticidad en la figura del cantautor, donde arte y vida son ámbitos dialogantes, por lo que en el caso de Silvio Rodríguez, "persona” y "protagonista” (Moore, 2012, p. 182) no se encuentran divorciados cuando se va configurando este ideario sobre lo femenino en su música.

Silvio Rodríguez ha sido una de las figuras fundamentales dentro del movimiento de la Nueva Trova Cubana. Sus canciones se caracterizan por tener textos herméticos y no fáciles de interpretar o de valorar. Agregamos a esto, una conciencia por parte de Rodríguez, que en los inicios de su carrera fue catalogado como un creador de canciones "raras" (Casaus y Nogueras, 2002, p. 22). Además el trovador señala: "Recuerdo que cuando mi generación empezó a cantar, parte de lo que hacíamos no se entendía. No sólo eran temáticas nuevas sino formas de hacer también distintas. Se agregaron palabras que no se usaban y la sintaxis se volvió personal" (Rodríguez, 2017).

No obstante esa "sintaxis personal" aludida por Rodríguez, se puede advertir en sus canciones un cierto imaginario acerca de lo femenino, que aparece en cómo el cantautor aborda a "la mujer" como figura que adquiere múltiples sentidos. Podríamos decir que dentro de este hermetismo lírico/musical particular de Silvio, se advierte un ideario femenino ecléctico que va desde lo que caracteriza a la mujer idealizada, la mujer disputada por dos hombres, la mujer perdida, el amor imposible de la mujer amada. La mujer madre, la mujer hija, la mujer mayor, la mujer y la rutina, la mujer emancipada, la mujer, la vida y el amor, la mujer y el amor cortés, la mujer que quiere ser hombre, la mujer erótica, entre otras, expresando un conjunto de connotaciones acerca de los sujetos femeninos aludidos: 


\begin{tabular}{ll}
\hline Canciones & Disco \\
\hline "Una mujer”. & $\begin{array}{l}\text { Rodríguez, Silvio. 1969/2006. Erase que se era, La Habana: } \\
\text { EGREM, Ojalá. }\end{array}$ \\
& \\
\hline $\begin{array}{l}\text { Tetralogía de mujer con } \\
\text { sombrero, }\end{array}$ & $\begin{array}{l}\text { Rodríguez, Silvio. 1970. Exposición de mujer con sombrero } \\
\text { [o “Tetralogía de mujer con sombrero"], La Habana: ICAIC } \\
\text { de Prado. }\end{array}$
\end{tabular}
de Prado.

\section{Ideario de lo femenino}

La figura de una mujer "no celestial", "no esperada" y la construcción de un amor significados como difícil: "pobre de todos los que amen así".

Relaciones entre la figura de una mujer con un sombrero pintada por Marc Chagall y la evocación de lo femenino a través de la propia experiencia amorosa.

\begin{tabular}{ll}
\hline $\begin{array}{l}\text { 1. "Apología de mujer con } \\
\text { sombrero". }\end{array}$ & $\begin{array}{l}\text { Rodríguez, Silvio. 1970. Exposición de mujer con sombrero } \\
\text { [o “Tetralogía de mujer con sombrero"], La Habana: ICAIC } \\
\text { de Prado. }\end{array}$ \\
\hline $\begin{array}{l}\text { 2. "Óleo de mujer con } \\
\text { sombrero". }\end{array}$ & $\begin{array}{l}\text { Rodríguez, Silvio. 1970. Exposición de mujer con sombrero } \\
\text { [o "Tetralogía de mujer con sombrero"], La Habana: ICAIC } \\
\text { de Prado. }\end{array}$ \\
\hline $\begin{array}{l}\text { 3. "Detalle de mujer con } \\
\text { sombrero". }\end{array}$ & $\begin{array}{l}\text { Rodríguez, Silvio. 1970. Exposición de mujer con sombrero } \\
\text { [o “Tetralogía de mujer con sombrero"], La Habana: ICAIC } \\
\text { de Prado. }\end{array}$
\end{tabular}

4. "Mujer sin sombrero".

Rodríguez, Silvio. 1970. Exposición de mujer con sombrero [o "Tetralogía de mujer con sombrero"], La Habana: ICAIC de Prado.

“Oh, mujer, si supieras..." Lo femenino idealizado.

"Una mujer se ha perdido". La mujer y la pérdida del amor, lo femenino desde la mujer perdida.

“¿Qué me dará la vida? ¿Qué me dará el amor?" Reflexiones sobre la vida y el amor, cuando se anhela ser "algo para una mujer".

"Yo apuesto todo a la mujer". Funcionario y poeta disputan el amor de una mujer. Lo femenino desde la mujer en disputa.

\begin{tabular}{ll}
\hline “Emilia”. & $\begin{array}{l}\text { Rodríguez, Silvio. 1970. Exposición de mujer con sombrero } \\
\text { [o “Tetralogía de mujer con sombrero"], La Habana: ICAIC } \\
\text { de Prado. }\end{array}$ \\
\hline "Madre". & $\begin{array}{l}\text { Rodríguez, Silvio. 1973. Canciones del grupo } \\
\text { experimentación sonora ICAIC [GESI], La Habana: EGREM. }\end{array}$
\end{tabular}

"Mujeres". Rodríguez, Silvio. 1978. Mujeres, La Habana: EGREM.

"Emilia, que horriblemente hermoso era aquel tiempo". Ideario femenino del amor que no fue.

"Madre en tu día, no dejamos de mandarte nuestro amor". Ideario de la mujer madre.

"Me estremeció la mujer" Ideario de diferentes mujeres (la mujer madre, la mujer del poeta, la mujer joven, los ojos de su hija, su abuela... un montón mujeres).

\begin{tabular}{|c|c|c|}
\hline “Cierta historia de amor". & Rodríguez, Silvio. 1978. Mujeres, La Habana: EGREM. & $\begin{array}{l}\text { "Aprendí de un buen amigo, a pegarle } \\
\text { a mi mujer, a llevar los pantalones } \\
\text { como es la tradición". Ideario de la } \\
\text { mujer mayor a través de una relación } \\
\text { tormentosa (violencia en pareja). }\end{array}$ \\
\hline "Imagínate". & Rodríguez, Silvio. 1980. Rabo de nube, La Habana: EGREM. & $\begin{array}{l}\text { "Imagínate que eres mi dama", "mi } \\
\text { último sueño" "que no eres de otro". } \\
\text { Ideario de lo femenino en el amor } \\
\text { adolescente a través del amor cortés. }\end{array}$ \\
\hline “El día en que voy a partir". & Rodríguez, Silvio. 1987. Memorias, Santiago de Chile: Alerce. & $\begin{array}{l}\text { "No te muevas, quiero conservar este } \\
\text { instante así, tu junto a la ventana } \\
\text { como a contra luz, echada en el lecho } \\
\text { queriendo mirar... Detrás de tu cuerpo } \\
\text { feliz, desnudo, desnudo, ya es el día en } \\
\text { que voy a partir". Ideario de la mujer } \\
\text { amada, desde el cuerpo femenino. }\end{array}$ \\
\hline
\end{tabular}

2 Estas cuatro canciones están dedicadas a "la mujer", que pueden ser varias o una. El sujeto es enunciado desde lo femenino, donde el accesorio del sombrero es fundamental. Accesorio usado como símbolo de feminindad en la belle époque. Las cuatro canciones resultan ser una evocación de un cuadro del pintor Marc Chagall, cf. Daza (2017). Según Silvio Rodríguez (2013): “Exposición de mujer con sombrero" o "Tetralogía de mujer con sombrero", no está dedicada a Emilia Sánchez, una mujer importante en la vida sentimental del trovador. 


\begin{tabular}{|c|c|c|}
\hline "Eva”. & $\begin{array}{l}\text { Rodríguez, Silvio. 1988. ¡Oh, melancolía!, Londres/La } \\
\text { Habana: The Point Studio/EGREM. }\end{array}$ & $\begin{array}{l}\text { "Eva no quiere ser para Adán” “Eva } \\
\text { cambió la señal” "Eva deja de ser } \\
\text { costilla", "Eva no cree en un príncipe } \\
\text { azul” Ideario de una mujer emancipada } \\
\text { y liberada de la figura masculina. }\end{array}$ \\
\hline $\begin{array}{l}\text { "Canción de invierno o } \\
\text { [Casi, Carmen, casi Gladys o } \\
\text { un poco de todo]". }\end{array}$ & Rodríguez, Silvio. 1984. Tríptico, La Habana: EGREM. & $\begin{array}{l}\text { "Es día de frío y llegas a casa. vienes } \\
\text { de la tarde cansada de un jueves. los } \\
\text { muebles, tu perro y millones de ojos } \\
\text { están, como siempre, esperando tu } \\
\text { vuelta". Ideario de una mujer que se } \\
\text { abandona a la rutina. }\end{array}$ \\
\hline "Y Mariana". & Rodríguez, Silvio. 1991. Silvio, La Habana: Fonomusic. & $\begin{array}{l}\text { "Un señor quisiera ser mujer y una } \\
\text { chica quiere ser señor". Ideario de } \\
\text { la mujer que quiere ser hombre, lo } \\
\text { femenino / lo masculino. }\end{array}$ \\
\hline “Desnuda y con sombrilla". & Rodríguez, Silvio. 1994. Rodríguez, La Habana: Fonomusic. & $\begin{array}{l}\text { "Tú, desnuda y con sombrilla, yo } \\
\text { vestido pero con calor" [...] "Tú } \\
\text { ardiente y sin capilla, yo quitándome } \\
\text { el sombrero alón”. Ideario de la mujer } \\
\text { erótica. }\end{array}$ \\
\hline
\end{tabular}

Tabla № 1. Idearios de lo femenino en las canciones de Silvio Rodríguez.

Lo femenino en estas canciones de Silvio Rodríguez es tratado desde aspectos afectivos y emotivos que surgen a modo de temáticas sobre múltiples mujeres, prevaleciendo como tópico transversal el binomio mujer/amor como dos caras de una misma moneda.

El ideario femenino en lo relativo al afecto amoroso como categoría en las canciones se enmarca dentro de los códigos de la "cultura heterosexual", cuya invención surge alrededor del siglo XII, cuando las mujeres comienzan a ser "cortejadas, celebradas, exaltadas" es en esta época cuando "las mujeres vieron resaltado su estatus simbólico" (Tin, 2012, p. 46). Y al mismo tiempo en este caso, ese ideario de exaltación a lo femenino en lo poético, se sitúa desde un discurso político del socialismo, que en términos utópicos aspira a un imaginario de la "mujer nueva", liberada, igual al hombre, emancipada. Sin embargo, en la práctica, desde la expresión musical, se advierte una mujer bastante idealizada.

Para Rodríguez no es necesario crear una canción dedicada expresamente a una mujer para hablar sobre su figura, como vemos en la Tabla № 1 , donde todas estas canciones tienen en común esa característica. La canción política para Rodríguez, tiene la función de formar, pero también, en el contexto del socialismo:

[...] en una patria liberada, en unas condiciones de construcción de una nueva sociedad, la canción política puede ser hasta la cancón amorosa [...] si damos una visión más perfecta, más humana, más 
revolucionaria de las relaciones entre el hombre y la mujer, esto también es político y esto también influye en la formación de los jóvenes, de la gente (Rodríguez, 1976).

Un discurso que de acuerdo con el contexto político e ideológico de la época, claramente apunta a un modelo de formación basado en las relaciones heterosexuales.

Por ejemplo la canción "Hoy mi deber era” (1982/1994), -y aquí enfatizamos en la relación entre lo femenino y lo político- presenta un matiz nostálgico ${ }^{3}$ tanto en su texto lírico como musical según veremos más adelante. El texto musical desde el punto de vista armónico ${ }^{4}$ se divide en dos secciones: la parte A-A' está en La menor, y en la parte B-B', se produce un cambio modal a Re mixolodio, como se aprecia en el siguiente cuadro:

Tonalidad inicial: Lam

Modulación: Re mixolidio

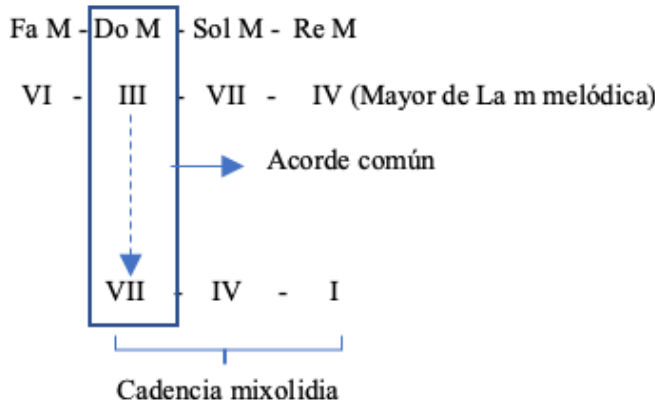

Diagrama № 1. Recorrido armónico desde B-B’.

En la parte A, la voz lírica masculina relata sus deberes políticos "Hoy mi deber era, cantarle a la patria / Alzar la bandera, sumarme a la plaza" a través de la secuencia armónica: I-IVm7-IIm7b5-V. A pesar de que la línea melódica al estar en modo menor en la parte Á, evoca tristeza y

\footnotetext{
${ }^{3}$ Desde el texto musical usamos la correspondencia atribuida a la tristeza -o, la nostalgia como una suerte de tristeza-, con las tonalidades menores, y a la alegría con las tonalidades mayores de acuerdo como ha sido significada desde la tradición de la música occidental. En sus inicios, con la tradición griega se consideraba una correspondencia entre un ethos y un estado emotivo, cf. Fubini (2005). Y más tarde en el barroco, a través de la teoría de los afectos, los modos mayores, la consonacia, los registros agudos y el tempo rápido se asociaban con la alegría; y los modos menores, la disonancia, los registros graves y el tempo lento, con la tristeza, cf. Alsina (1997).

${ }^{4}$ Otra forma de explicar el comportamiento armónico de esta canción, es que en su totalidad funciona en La menor melódica, cuya secuencia armónica en la parte A-A', es I-IVm7-IIm7b5-V, con un uso de acordes poco frecuentes en su recorrido armónico en la parte B-B' VI-III-VII-IV, donde el VII grado [Sol Mayor] y el IV grado [Re Mayor], serían acordes de La menor (natural y melódica, respectivamente), pero como existe un final de frase y reposo en el acorde de Re Mayor, esto nos llevaría a sostener que se produce un giro cadencial modal en este punto, correspondiendo en este acaso a una cadencia mixolidia en Re, y por lo tanto el análisis se desarrolla tomando en cuenta este giro.
} 
melancolía, el texto lírico en un juego de expresividad antagónica, es más bien luminoso y esperanzador: "Hoy era un momento más bien optimista / Un renacimiento, un sol de conquista".

Luego en la parte B-B' pasa al VI grado [Fa Mayor], y en el siguiente acorde que corresponde al III grado [Do Mayor], se produce una modulación (modal) a Re mixolidio donde ese Do Mayor, ahora convertido en VII grado, funciona como un acorde común cuya progresión nos lleva a la cadencia mixolidia: VIIIV-I. La enunciación del texto lírico en esta cadencia refiere a la ausencia de la mujer amada: "Pero tú me faltas hace tantos días / Que quiero y no puedo tener alegrías / Pienso en tu cabello que estalla en mi almohada / Y estoy que no puedo dar otra batalla". Acá nuevamente vemos una relación de expresividad antagónia entre lo que enuncia el texto lírico y musical respectiavmente. Se produce aquí una sensación de reposo en el I grado del nuevo modo, que contrasta con el texto lírico que evoca más bien un sentimiento de tristeza: "No puedo tener alegrías" y "No puedo dar otra batalla".

"Hoy mi deber era" es una canción que surge a partir de una experiencia puntual, como resultado de una situación nostálgica amorosa, como lo expresa el trovador: "quise hacer una canción patriótica sobre la fecha, pero yo estaba tan jodido de no ver a esa mujer en tanto tiempo que lo que me salió fue esta canción, me salió una explicación, que es la canción; una explicación de la canción de que no puedo hacer la canción que debo hacer" (Rodríguez, s/f).

En este caso, la nostalgia amorosa en Rodríguez, pesa más que el deber político, y por tanto lo sobrepasa, dirigiendo su atención hacia el afecto, donde lo político y el amor idealizado están presentes como dos ámbitos coexistentes y dialogantes.

El hablante lírico ha logrado cantarle a la patria, alzar la bandera, sumarse a la plaza, pero al mismo tiempo, ha soñando su abrazo, volando a su lado. En este caso, la evocación de lo femenino en el contexto político señalado en la canción, no necesariamente implica la enunciación de una compañera con las características de la "nueva mujer" (Kollontái, 2016, pp. 84-85), vale decir, una mujer libre, con igualdad de derechos; que a pesar de la distancia, sea imaginada como una mujer protagonista en el escenario político. La mujer descrita por Silvio Rodríguez en la canción, es una mujer que evoca nostalgias, es más bien una mujer para el amor y no para la patria. Lo interesante en este primer ejemplo, es la complejidad en el uso tonal/modal que nos lleva a comprender cómo a través de la configuración armónica se expresa musicalmente la relación entre texto musical/texto lírico y enunciación 
sentimental, donde el uso modal en Re mixolidio, que habitualmente es significado como alegre, en el contexto de La menor su sentido cambia al ser usado para expresar sentimientos nostálgicos y tristes.

En la canción “Con diez años de menos” (1980), la enunciación sentimental resulta interesante por la manera en que se utiliza un importante cambio modal y de tempo, recursos que logran enriquecer el discurso musical.

La canción tiene una estructura A/B. La parte A, está en Sol Mayor, cuya secuencia armónica es: IV-V-VII-VI-II-VII-V6-I, donde se expone una reflexión acerca del tiempo: "Si fuera diez años más joven qué feliz / Y qué descamisado el tono de decir / Cada palabra desatando un temporal / Y enloqueciendo la etiqueta ocasional..." Este fragmento, está estructurado con un ámbito melódico de extensión breve, con bastante uso de grados conjuntos, sin embargo presenta un tempo animado en relación a la parte B. En la parte A', ocurre un cambio modal, donde se sustituye el acorde de dominante que sería un Si7 a través de una función transitoria, empleando una cadencia frigia con Fa-Mim, luego vuelve a la tónica con función transitoria, en este caso con la cadencia auténtica V6-I.

Se comienza a parepar una modulación en La menor, donde el Fa Mayor es el acorde común, que es el sexto grado de La menor, luego se usa un Sim7b5 y un Mi4/Mi, II y V grado de La menor respectivamente, con esta secuencia armónica: II-V-I: "Para sacar chispas del agua que me das / Para empuñar la alevosía y el candor, y saber olvidar mejor...”, produciéndose aquí un intercambio modal, pues, en lugar de ir a La menor, va a La Mayor mixolidio al usar la cadencia I-VII-IV6 logrando una sensación de reposo, no sólo con este recurso en la armonía, sino también al cambiar el tempo, justo cuando refiere al sujeto que es la mujer. Como si Rodríguez tratara de destacar el momento en que refiere a la mujer: "Esta mujer propone que salte y me estrelle / la tierra con el viento, la luz con la sombra..., Rodríguez, dispone de estos recursos tras el uso de a una voz masculina íntima y sensible, logrando una evocación de lo femenino, desde el amor. Y es que el amor para Silvio: "Es como una necesidad, un camino que se escoge" (Rodríguez, 2017), lo que se traduce en un tópico recurrente en su propuesta musical.

\section{Música y revolución: ideario del Hombre nuevo en la Nueva Trova Cubana}

La noción de Hombre nuevo basado en los postulados de Ernesto Guevara, fueron fundamentales en el contexto del movimiento de la Revolución 
Cubana. Particularmente en el movimiento artístico de la Nueva Trova Cubana, liderada por Silvio Rodríguez, Pablo Milanés, Noel Nicola, Amaury Pérez, Sara González, entre otros. Este proyecto artístico cobró visibilidad a partir de la formación del Grupo de Experimentación Sonora (GESI) del Instituto Cubano de Arte e Industria Cinematográficos (ICAIC), creado en 1959, como un espacio para la difusión artística y cultural, en el marco de la Revolución Cubana y la consolidación identitaria de América Latina. Es así como:

El Instituto Cubano de Arte e Industria Cinematográficos (ICAIC) y Casa de las Américas, constituyeron polos ideológicos que sustentaron la presencia del latinoamericanismo, la conciencia del subdesarrollo y el antiimperialismo en la agenda del cine, la música, las artes visuales y la literatura, todo esto a través de encuentros, publicaciones y de la circulación de obras y autores (Guerrero y Vuskovic, 2015, p. 2).

La identificación con el Hombre nuevo en este contexto artístico y cultural fue importante para la renovación política a través de un summum, comprendido en una figura concreta y material. En este sentido, Guevara sostiene que: "para construir el comunismo, simultáneamente con la base material, hay que construir al hombre nuevo" (1979, p. 11). El énfasis de esta construcción, radica en la importancia de la conciencia individual y colectiva acerca de los mecanismos de dirección y producción de manera interdependiente, por lo que el hombre "así logrará la total conciencia de su ser social, lo que equivale a su realización plena como criatura humana, rotas las cadenas de la enajenación" (Guevara, 1979, p.14).

El movimiento de la revolución entonces propondrá una nueva moral, considerada un ethos, un nuevo modo de ser, pues el "mecanismo de movilización de las masas" [...] para Guevara, "debe ser de índole moral”. Así, el autor señala que la "educación prende las masas y la nueva actitud preconizada tiende a convertirse en hábito" (Guevara, 1979, pp. 11-12), ello, para crear al Hombre nuevo, quien se transforma en una figura referente y un ideal colectivo. El Hombre nuevo, libre de enajenación se advierte entonces en "la reapropiación de su naturaleza a través del trabajo liberado y la expresión de su propia condición humana a través del arte y la cultura" (Guevara, 1979, p. 15).

Cuando Guevara, piensa en un Hombre nuevo, podríamos decir que intenta problematizar esa categoría de hombre, que estaría más bien vinculada a una noción de hombre viejo. Uno que se ha adecuado históricamente a la supervivencia irreflexiva de su labor dentro de un espacio social, 
traspasado por unas condiciones político-económicas. Siendo clave en este Hombre nuevo, la conciencia acerca de su importancia social e histórica, para llegar a tensionar ese modelo de hombre alienado, propio de su paso e inmersión en el sistema capitalista.

El Hombre nuevo de Guevara, en su aparición histórica, permite un interesante diálogo con el Hombre nuevo que antaño ofrecía la perspectiva cristiana, según el Apóstol Pablo, pregonada en el Nuevo testamento, que a su vez, cobra relevancia en el escenario político de América Latina con la Teología de la Liberación. Se discute que "tanto para algunos cristianos como para ciertos marxistas en Latinoamérica, se entiende al hombre nuevo como la culminación de un proceso de liberación, pudiendo encarnar tanto al sujeto individual como a un bloque histórico o sujeto colectivo" (Rojas, 2017, p. 3).

La idea de renovar lo antiguo, lo anterior, por lo nuevo, puede considerarse una expresión simbólica y colectiva que encontramos a menudo en los movimientos sociales y culturales, a partir de ordenes de tipo político e ideas progresistas que intentan formular nuevas visiones, nuevos modos sobre el ser, el hacer y el quehacer humano, como por ejemplo: la Nueva canción chilena, El canto nuevo. 0, la idea del Nuevo Cine Latinoamericano, promovida desde Instituto Cubano de Arte e Industria Cinematográficos (ICAIC), con el fin de difundir un cine desde una vertiente cultural y social políticamente comprometida. Todos ejemplos de una búsqueda transformada en un fenómeno de renovación.

La relevancia de estos proyectos artísticos se inscribe dentro de un imaginario utópico, que pasada la Revolución Cubana, se hace necesario cuidar y mantener. Es así como:

Su carga utópica, sin embargo, se había ido articulando durante todos los años sesenta a otros discursos e imaginarios políticos que estaban circulando en toda América Latina: entre ellos, el paradigma del desarrollo se convertiría en un punto de referencia esencial para la redefinición y la reformulación cultural de las esperanzas puestas en el proceso revolucionario (Peris, 2011, p. 250).

Canciones como "Cuando digo futuro" (1977/1994), o "Canción de la nueva escuela" (1972/1994) ${ }^{5}$ de Silvio Rodríguez, remiten a un futuro que debe

5 “Canción de la nueva escuela” [o, "La nueva escuela”], es una canción creada para la banda sonora de la película No tenemos derecho a esperar (1972) de Rogelio Paris. 
ser cuidado bajo la prolongación de los supuestos de la revolución, y es enunciado por el trovador, siendo por ello un portavoz artístico.

La canción "Cuando digo futuro", inicia con una guitarra arpegiando un ritmo animado, y dos flautas traversas que se suman para reforzar la invitación de Rodríguez: "Te convido a creerme cuando digo futuro / Si no crees mi palabra, cree en el brillo de un gesto / Cree en mi cuerpo / Cree en mis manos/ Que se acaban".

La "Canción de la nueva escuela", con ritmo de son y una instrumentación base conformada por: piano, guitarra, contrabajo y percusión latina (claves, bongó y congas), es interpretada por Silvio Rodríguez, con un segunda voz de apoyo de Pablo Milanés.

La canción es de estructura binaria A-B, A está en la tonalidad de en La menor. Luego en la parte $B$, pasa a La Mayor produciéndose un contraste modal tonal, con Silvio como protagonista en la voz. Aquí el texto musical y lírico viene a reforzar el mensaje de esperanza en el proyecto revolucionario, cuando dice: "Estos que continuamos / Bajo la sombra más que aguerrida / De aquella semilla, / Vemos en estos muros / Un preludio del futuro / Que lo bueno de los años duros / Salvaron ayer".

Lo masculino, en Silvio, se proyecta tanto en "el hombre" o "los hombres" de la revolución, como lo describe en "El mayor", en la "Canción del elegido" o en "Playa girón", como también en una figura masculina concreta, como lo es el Che Guevara, en múltiples homenajes musicales que Rodríguez le brinda.

Es así como la Nueva Trova Cubana de Silvio Rodríguez, preconiza al Hombre nuevo a partir de la figura de Ernesto Guevara. En este sentido, Silvio, comenta: "Está "La era", está "Fusil", "América te hablo de Ernesto", "La oveja negra", yo la hice pensando en el Che y pensando en Cuba también" [...] "La era yo la compuse unos meses de desaparecido el Che" (Rodríguez, 1992).

Rodríguez, explica que "en la medida que han ido pasando los años, yo he procurado no perder la óptica del niño" sin perder la capacidad de asombro en los temas de la revolución, en cuyo gesto se advierte una gran conexión con Guevara, cuando explica: "le he cantado, porque he hablado muchas veces del Che, siempre lo menciono. Debe ser porque alguna vez quise parecerme a él [...] un hombre que actuaba como pensaba" (Rodríguez, 1992). En la canción "Hombre”, Silvio le pide al Che: 
Que descienda a mi ciudad tu ejemplo, [pues] a medida que han ido pasando los años, la presencia del Che es como imborrable [...] una de las cosas que siempre me sucede desde hace muchos años cuando pienso en el Che, es el pesar no solamente por su pérdida, sino porque no esté en estos momentos entre nosotros, porque cuánto ayudaría su visión, su pensamiento, su audacia en estos momentos (Rodríguez, 1992).

La noción de hombre, en Silvio Rodríguez, en su sentido ontológico, se aprecia de manera poderosa desde al campo político, como hemos revisado en sus homenajes a figuras como el Che Guevara, Fidel Castro y el ideario del Hombre nuevo. Y desde el punto de vista musical y poético, José Martí y el trovador Antonio Sindo Garay, que para Silvio Rodríguez se convierte en su gran referente musical (Rodríguez, 1992). Por lo tanto, lo político y el arte son dos elementos que conforman el fundamento de la Nueva Trova Cubana, teniendo como referentes a figuras masculinas. Para Hernández (1976) la canción política promueve la idea del hombre mejor, y para Rodríguez:

Siempre las guerras de las independencias, las inician hombres muy avanzados, hombres generalmente muy ilustrados y por supuesto con una formación cultural, estética cercanos las artes, muchas veces artistas, grandes artistas como el caso de Martí. La vocación artística tiene mucho que ver con la vocación libertaria y son dos cosas que se complementan. Una de las cosas que más me sobrecoge de Céspedes, es la soledad en que muere, pero también el ejemplo que significa su muerte [...] Céspedes, para un trovador como yo, también tiene sustancias adicionales, podría decirse, porque también fue poeta, y no un mal poeta, un hombre muy ilustrado, un hombre de temperamento más bien brioso, enamoradizo en su juventud parece que bastante trasnochador y hasta juerguista, o sea toda una serie de ingrediente humanos que mi me lo acercan muchas, y que sea autor o coautor de una de las canciones de amor cubanas que es la bayamesa ${ }^{6}$ (Rodríguez, 2000).

A pesar que el concepto de Hombre nuevo en la Revolución Cubana siempre apuntó a un ideario masculino, la presencia femenina fue muy importante en diferentes formas. Particularmente en el inicio del movimiento de la Nueva Trova Cubana, la participación de Haydeé Santamaría (1923-1980),

${ }^{6}$ Ver versión de Silvio Rodríguez de "La bayamesa". Recuperado de https://www.youtube.com/ watch?v=DLxVOkvEZyw 
fue una figura clave según comenta Silvio Rodríguez: “Haydeé Santamaría [...] había hecho un Festival de la Canción Contestataria, de la Canción Protesta [...] Casa de las Américas [...] nos abrieron las puertas para que hiciéramos conciertos desde ahí" (Rodríguez, 1992).

Santamaría había sido parte del Ejército Rebelde, compuesto de mujeres. Fue combatiente del Moncada, fundadora y directora de la Casa de las Américas, política, feminista revolucionaria y partisana, que producto de una depresión se suicidó en 1980. Finalmente resultó ser la creadora y patrocinadora del movimiento de la Nueva Trova, ${ }^{7}$ que se caracterizó por tener una nueva sonoridad que se diferenciaba de la música cubana de aquel entonces en términos musicales, y en términos líricos, puesto que daba un giro hacia temáticas vinculadas con la revolución.

\section{¿Mujer nueva? ¿ ¿Mujer nueva masculinizada en la Revolución Cubana?}

El concepto de Mujer nueva al que aludimos aquí, lo asumimos de Alexandra Kollontái (1872-1952), política y revolucionaria rusa que teorizó sobre la situación de la mujer de principios del siglo XX en el espacio social, tanto público como privado, desde una perspectiva material histórica y llanamente marxista. Para Kollontái: “A medida que la mujer interviene en el movimiento de la vida social, a medida que se convierte en resorte activo del mecanismo de la vida económica, su horizonte se ensancha" (2000 [1977], p. 46).

La Mujer nueva, de Kollontái (2000 [1977]), aparece prefigurada a partir de los rasgos de las heroínas de la literatura moderna de su época. Igual que lo que ocurre con la alegoría del "viejo hombre" y del "nuevo hombre" bíblico (Santa Biblia, Efesios, 2012, 4: [22], pp. 259-260; Santa Biblia, Colosenses, 2012, 3: [9], p. 272). Así también existe una mujer del pasado, que es antagónica a la mujer del nuevo tipo, pues dice la autora "mientras los literatos se esforzaban en dibujar tipos de mujeres del pasado, que la vida hacía desaparecer, la realidad rusa del período comprendido entre 1870 a 1880, producía figuras del nuevo tipo de mujer" (Kollontái, 2000 [1977], pp. 13-14).

Las características que definen a esta Mujer nueva, surgen a raíz del modo en que desarrolla un nuevo tipo de relación con los hombres desde su

${ }^{7}$ Más información sobre Haydeé Santamaría, cf. Randall (2015). 
sexualidad, ${ }^{8}$ donde lo esencial en ella "es la base moral" (Kollontái, 2000 [1977], p. 41). La Mujer nueva, se visibiliza en:

La disciplina en vez de un sentimentalismo exagerado; la apreciación de la libertad y la independencia en vez de la sumisión y de la falta de personalidad; la afirmación de su individualidad y no los esfuerzos estúpidos por comprometerse con el hombre amado; la afirmación del derecho a gozar de los placeres terrenales y no la máscara hipócrita de la pureza, y, finalmente la subordinación de las aventura de amor a un lugar secundario en la vida. Ante nosotros tenemos, no una hembra, ni una sombra del hombre, sino una mujer-individualidad (Kollontái, 2000 [1977], p. 53).

La autora desarrolla una abierta crítica a los postulados del feminismo de la igualdad, donde uno de los propósitos más importantes era la lucha por lograr la igualdad de la mujer respecto del hombre, a través de la conquista de los espacios que habían sido ocupados históricamente por ellos. La crítica de Kollontái (2016) a esta visión feminista remueve los presupuestos que inciden en cuestiones estructurales del capitalismo que según ella, el feminismo burgués no contempla. Para la autora: "las mujeres pueden llegar a ser verdaderamente libres o iguales sólo en un mundo organizado mediante nuevas líneas sociales y productivas" (Kollontái, 2016, p. 71).

Así también, Kollontái (2016) distingue entre dos visiones antagónicas sobre cómo se comprende el fenómeno de la liberación femenina. Distingue por una parte los idearios de la mujer burguesa, que pretende su liberación desde un lugar de privilegio. Y por otra, los de la mujer proletaria que pretende liberarse desde su doble explotación; la del hombre y la del trabajo. Su propuesta aquí es discutir la noción de la categoría mujer, entendida como única y absoluta, por ello la autora rusa señala:

Mientras que para las feministas la consecución de la igualdad de derechos con los hombres en el marco del mundo capitalista actual representa un fin lo suficientemente concreto en sí mismo, la igualdad de derechos en el momento actual para las mujeres proletarias es sólo un medio para avanzar en la lucha contra esclavitud económica de la clase trabadora (Kollontái, 2016, p. 74).

\footnotetext{
${ }^{8}$ En su propuesta, la autora excluye el tema de las múltiples identidades de género, y el modo en que se comprende la sexualidad femenina, asumiendo a esta nueva mujer desde una visión sexual más bien heteronormativa.
} 
Por lo tanto a través de esta crítica, desvela la ideología sobre el modo en que se comprenden la relaciones sociales que afectan a la dimensión política, económica y de clase, no de "la mujer", sino de las mujeres, en plural. Las burguesas, las proletarias y las campesinas, que de acuerdo a los postulados del marxismo, la interacción de ellas en el sistema económico crearía relaciones que se encontrarían invertidas desde su base. Por ello, sentencia que mientras no se produzcan cambios estructurales en estas tres dimensiones (política, económica y de clase), no cambiará la situación de las mujeres (Kollontái, 2016).

Son interesantes los matices que se producen en esta noción de la Mujer nueva de Kollontái, y que de algún modo son asumidos en el contexto de la Revolución Cubana de 1959. Si las feministas en su condición de burguesas "ven al hombre como el principal enemigo" debiendo conquistar los mismos espacios y privilegios que ellos han conseguido, la Mujer nueva, desde su conciencia de clase: "no ve a los hombres como el enemigo y el opresor, por el contrario, piensan en los hombres como sus compañeros, que comparten con ellas la monotonía de la rutina diaria y luchan con ellas por un futuro mejor" (Kollontái, 2016, p. 75).

El contexto de la Revolución Cubana y la mujer demuestra la existencia de agrupaciones que tienen como fin otorgar importancia a su figura, como lo son: la Federación de Mujeres Cubanas, creada en 1960, un año después del triunfo de 1959, cuyo principal objetivo fue el de lograr "la incorporación de la mujer a la sociedad y al empleo, así como al programa de cambios sociales y económicos en marcha en el país". 9 Antes de esta federación, hubo otras organizaciones previas que intentaron de uno u otro modo, posicionar el trabajo femenino en ese contexto, tales como: la Unidad Femenina Revolucionaria, la Columna Agraria, las Brigadas Femeninas Revolucionarias, los Grupos de Mujeres Humanistas y la Hermandad de Madres. ${ }^{10}$

En estas organizaciones existe un interés por promover derechos de igualdad respecto de los temas de género, como la Ley de la Maternidad (Ministerio de Justicia de Cuba, Decreto Ley № 339, 1974), el Código de la Familia (Ministerio de Justicia de Cuba, Ley № 1289, 1975), la Ley de Protección e Higiene del Trabajo (Comité Estatal de Trabajo y Seguridad, Ley, № 13,1977), entre otros. Sin embargo, en todas estas iniciativas no se advierte una crítica a la ideología patriarcal basada en una estructura

\footnotetext{
${ }^{9}$ Recuperado de https://www.ecured.cu/Federaci\%C3\%B3n_de_Mujeres_Cubanas

${ }^{10}$ Recuperado de https://www.ecured.cu/Federaci\%C3\%B3n_de_Mujeres_Cubanas
} 
social masculina, siendo de alguna forma, el soporte político, legislativo y social que norma el ser mujer en Cuba. Estudios dicen que:

A pesar de que la Revolución Cubana, y especialmente las organizaciones nacidas posteriormente a ella, se caracterizaron por la mayor participación femenina en términos cualitativos y cuantitativos, el concepto de hombre nuevo es originado en la mente de un hombre-masculino, en el contexto masculino de la guerra de guerrillas (Vidaurrázaga, 2012, p. 70).

La mujer en el contexto de la guerrilla es instrumentalizada en favor de un ideario masculino y masculinizante, como lo es el concepto del hombre nuevo, y sus postulados ético-políticos, polarizando la categoría de lo masculino en lo femenino.

La Revolución Cubana fue un espacio donde la dominación masculina delimitó y reguló el modo del comportamiento femenino, creando un ethos de la guerrillera, modelado a partir de una suerte de inhibición implícita de lo femenino dentro de un espacio masculino, con el fin de mantener la estabilidad ideológica de la guerrilla y del sistema socialista.

La nueva moral revolucionaria impone el ideal de: "El hombre nuevo -al que estas guerrilleras quería emular, aun cuando fuera imposible convertirse en un hombre- era un sujeto sumamente ejemplar, sacrificial y heroico" (Vidaurrázaga, 2012, p. 72).

La mujer guerrillera, entonces, asume una función combativa desde lo que será una performatividad masculina, ${ }^{11}$ a través la negociación simbólica en la asunción de roles masculinos, ya que:

Si los atributos y actos de género, las distintas formas en las que un cuerpo revela o crea su significación cultural, son performativos, entonces no hay una identidad preexistente con la que pueda medirse un acto $o$ atributo [...] El hecho que la realidad de género no se determine mediante actuaciones sociales continuas significa que los conceptos de un sexo esencial y una masculinidad o feminidad

\footnotetext{
${ }^{11}$ Ver imagen sobre aspectos relacionados con la masculinización femenina a través del uso de uniformes de combate en el contexto de la revolución. Imagen recuperada de http://www.granma.cu/ cuba/2017-04-23/la-primera-mujer-en-el-ejercito-rebelde-23-04-2017-21-04-09. El registro de la imagen es en el Pico Turquino, donde se encuentran Celia Sánchez (al centro), junto a Raúl Castro, Ciro Redondo, Haydée Santamaría, Julito Díaz González, y Efigenio Ameijeiras. foto: Oficina de Asuntos Históricos.
} 
verdadera o constante también forman como parte de la estrategia que esconde el carácter performativo del género y las probabilidades performativas de que se multipliquen las configuraciones de género fuera de los marcos restrictivos de dominación masculinista y heterosexualidad obligatoria" (Butler, 2007, p. 275).

Podríamos decir que la noción de lo femenino en la mujer cubana, en el contexto de la revolución, proviene de ciertos presupuestos del feminismo de la igualdad, considerando que "el discurso de este movimiento mantiene como ideal al ser masculino y por lo tanto busca identificar a las mujeres a partir de ese ideal, que serían los atributos y capacidades asignados a la masculinidad" (Montesinos, 2002, p. 20). En este sentido, la figura masculina se convierte en el ejemplo a seguir para las guerrilleras de la revolución, justamente desde la noción de una femineidad basada en atributos que históricamente han sido asumidos culturalmente como masculinos, como lo son la guerra y lo heroico.

Dentro de este escenario político, surge Sara González, única trovadora en los inicios del movimiento de la Nueva Trova, junto a Silvio Rodríguez, Pablo Milanés, Noel Nicola, entre otros. Resulta interesante notar ciertos diálogos con lo masculino en las propuestas musicales de Sara González, como lo es su participación en la canción política donde el ideario del hombre nuevo es la base del movimiento, y también su desarrollo artístico al interior de una tradición musical masculina. Por último, la homosexualidad de Sara González es un factor que podría complejizar el análisis sobre su función como mujer músico dentro del régimen socialista.

\section{Sara González: ideario de la mujer encarnada y el movimiento de la Nueva Trova}

La presencia de Sara González, la única mujer creadora que formó parte del movimiento de la Nueva Trova, nos permite dar cuenta de un quiebre en el paradigma revolucionario respecto de lo femenino/masculino dentro del contexto artístico. ${ }^{12}$ Podemos decir que con la presencia de Sara

\footnotetext{
${ }^{12}$ No es que no hubiera otras mujeres músicos antes de Sara González, en la tradición musical cubana. En este sentido, podemos mencionar a varias mujeres. Por ejemplo, como precedente de la canción de la Trova, de la escuela de la vieja Trova es el caso María Teresa Vera (1895-1965). Luego, Marta Valdés (1934) más acercada al "filin" cubano y el bolero. Así también, Teresita Fernández (1930-2013), considerada como una excelente cantautora y creadora de música para niños. Por otro lado, están Marta Campos (1954) Rita del Prado (1961) Yamira Díaz, cantautoras de una generación posterior a Sara González, cuyo trabajo musical se enmarca mayormente en canciones infantiles y amorosas, que han sido vinculadas a la novísima Trova.
} 
González, se advierte un cambio de sentido y significado de lo femenino, que se muestra en el paso de la mujer objeto de idealización, a la mujer encarnada, ahora como sujeto creador. Las primeras creaciones musicales de Sara González, principalmente canciones y musicalizaciones, surgieron a partir del trabajo que realizó con el Grupo de Experimentación Sonora (GESI), conformado principalmente por figuras masculinas. ${ }^{13}$

González, cuenta que fue un poco difícil su incorporación al GESI, pues, revela ciertas resistencias de su participación en el grupo. Se argumentaba que la trovadora no tenía experiencia como músico, según señala:

Tenía una persona con reservas ¿esto dará resultado? [...] porque realmente yo no venía de nada, yo venía de estudiar música [...] yo no vengo de una historia como la que tenía el mismo Pedro Luis [Ferrer] o el mismo Mike [Porcel] [...] de repente ésta que no había cantado nada, que nadie la conocía. De repente llega y canta un tema de no sé qué y hace un programa de televisión con Pablo Milanés (González, 2012).

Otro aspecto en que se ve un diálogo con lo masculino, es el primer trabajo discográfico de Sara González. Se trata de la musicalización de una selección de versos de José Martí, titulado Versos José Martí (1979), en homenaje al político, escritor y filósofo cubano, como también lo había hecho la trovadora Teresita Fernández, conocida en Cuba como la cantora mayor, en su trabajo Teresita canta a Martí (1968/2007). ${ }^{14}$ Trabajo que en el caso de Sara González, fue sugerido por Silvio Rodríguez y Pablo Milanés, en los inicios de su carrera musical. Frente la pregunta del músico Amaury Pérez, ¿Cuándo aparece la Trova, la Nueva Trova? Sara, responde: "Ahí empiezo yo [...] en el concierto del 67 de la canción política, y yo voy y canto, allí, y me vieron varia gente cantando, pero yo no canté con guitarra, yo canté La era, una cosa de esas, o algo por el estilo. Y ahí es donde yo hago mis primeras cosas... [Con Silvio Rodríguez] (González, 2012).

La masculinización estilística de la trovadora es un aspecto a tener en cuenta para comprender qué atributos musicales van definiendo su

\footnotetext{
${ }^{13}$ Ver imagen de los/as integrantes del Grupo de Experimentación Sonora (GESI), donde aparece Sara González (cantautora/trovadora) en la segunda fila, segundo lugar de iz. Las otras dos mujeres que se ven en la imagen son intsrumentistas. Recuperado de https://www.cancioneros.com/ ct/33/0/grupo-de-experimentacion-sonora-del-icaic

${ }^{14}$ Así también Pablo Milanés dedica un disco a Martí "Versos a José Martí" (1974) y Amaury Pérez en "Poemas de José Martí cantados por Amaury Pérez" (1978). Ver en: www.cancioneros.com En este gesto de homenaje de cuatro destacados trovadores y trovadoras cubanas, se aprecia una importancia referencia a esta figura masculina, considerado como quien contribuyó a la independencia en Cuba, por lo tanto se trata de un personaje fundacional para la república.
} 
supervivencia artística dentro de este mundo masculino. En este sentido, se comenta que: "las artistas femeninas [...] han tenido que adoptar una estética más masculina para ser aceptadas en igualdad de condiciones respecto de los hombres. A veces son cómplices en su propia devaluación, pero han desarrollado una serie de formas para abordar de manera creativa su papel en la Trova"15 (Graper, 2014, p. 4).

En términos sonoros y tímbricos, podríamos decir que la voz del trovador se hereda a la voz de la trovadora, o quizás es emulada. Esto se evidencia en un gesto vocal que podría ser considerado como "masculinizado", con un timbre vibrado, donde Sara logra una voz que podríamos llamar: "asilviada". De hecho, la voz de Sara, se llegaba a confundir con la de Silvio: "en aquella época la gente no sabía si era Silvio", o Sara -cantando la canción- “Un hombre se levanta (1973), por el tono” (Pérez, 2012). Pero a esto podemos agregar que esa voz del trovador como sujeto masculino, según los cánones vocales, podría ser considerada más bien femenina, debido al uso agudo que le da. En este sentido, las categorías de lo femenino y lo masculino en los usos de la voz se comportan de manera móvil e intercambiable en su performatividad, a través de un desplazamiento en los modos de su significación.

Un ejemplo donde se produce una suerte de mímesis vocal entre los trovadores, Silvio y Sara, es la canción "Querer tener riendas" (1998). ${ }^{16}$ Una canción amorosa, de forma binaria, en compás binario o cuaternario (2/4 o 4/4), que se basa en un acompañamiento de guitarra, con un ostinato rítmico-melódico. Este se mantiene en gran parte de la canción, con excepción de una alternancia entre el ostinato en una dinámica de piano y un rasgueo enérgico en forte, respectivamente, en el verso: "Haz como si estuvieras en guerra / Báñame de rocas y de tierra”. La canción en la parte $B$, presenta un mayor énfasis dinámico y de su tempo, respecto de la parte A, gracias a la instrumentación en un ritmo de son.

Dentro de este escenario masculino y hasta cierto punto masculinizante, destacamos en Sara González, varios aspectos en los que existen diálogos con el mundo femenino. Por ejemplo, su formación musical estuvo marcada por Leopoldina Núñez, profesora de guitarra. Sara González, de algún modo considera que Núñez es una referente musical para ella: "Leo

\footnotetext{
${ }^{15}$ Female performers, on the other hand, have had to adopt a more masculine aesthetic in order to be accepted on equal terms with men. They are at times complicit in their own devaluation, but have developed a variety of ways to creatively address their role in Trova. La traducción es nuestra.

${ }^{16}$ Canción escrita por Silvio Rodríguez, en 1973. Versión de Sara González, disco Mírame, 1998. Recuperado de https://www.youtube.com/watch?v=Zc_rGRiM6MM
} 
es una mujer maravillosa, una de las mejores profesoras de guitarra que ha habido en este país, la verdad [...] ya era muy conocida la labor como profesora de Leopoldina... formó a mucha gente" (González, 2012).

En este gesto de reconocimiento a Leopoldina Núñez, como una importante referente en su formación musical, Sara valora una tradición de enseñanza femenina. Esto es muy propio del feminismo de la diferencia "que busca reivindicar lo femenino, al no definirse como lo otro de la masculinidad" (Montesinos, 2002, p. 22), sino que encontrar en la figura de la mujer un orden simbólico de autoridad y una fuente de libertad.

Así mismo, y como otro gesto de reivindicación de lo femenino, la trovadora desarrolla un proyecto musical titulado Cantos de mujer. Se trata de dos trabajos discográficos dedicados a difundir la propuesta musical de diferentes figuras femeninas: "Esta vez con la colaboración del poeta Sigfredo Ariel hemos seleccionado un repertorio de canciones escritas por mujeres que pertenecen a varias generaciones" (González, 2011), señala la trovadora.

Los dos discos son publicados en 2003 y 2009, -con un tercero que al parecer no alcanzó a grabar-, según comenta González, enfatizando en la importancia de visibilizar la creación femenina: "Ya empiezo a trabajar para un tercer disco, para grabar el próximo año, y si hay más canciones, haré otros, porque no se trata de una antología, es una recopilación, que rescata la obra de compositoras, muchas veces con temas muy conocidos, pero que no se reconocen como creaciones de una mujer" (González, 2009).

En el segundo álbum, González, incluye la canción "Ausencia” (1999) de la trovadora Liuba María Hevia, que en su versión original interpreta junto con Silvio Rodríguez, con el fin de difundir su trabajo en este proyecto Cantos de mujer.

Otro vínculo de González, con lo femenino en su condición de mujer músico revolucionaria, es el homenaje a Haydée Santamaría, que logra al musicalizar el poema "A una heroína de la patria" (1980), escrito por Fina García Marruz, poetisa cubana. La canción es entonces un homenaje a esta heroína cubana, guerrillera, figura importante de la revolución, directora de Casa de Las Américas, que como señalamos más arriba, fue gestora del movimiento de la Nueva Trova Cubana, que se suicida a los cincuenta y siete años de edad, a quien Sara, reconoce como "madrina" (González, 2012). 
De una u otra forma, Sara González y Silvio Rodríguez reconocen en la figura de Haydée Santa María, a una referente importante dentro de sus carreras artísticas en el marco político revolucionario, según Rodríguez:

Yo le debo a Haydee, por ejemplo, una comprensión más cercana, menos mítica de la revolución, porque Haydee nos hablaba de Abel, del Che, de todos esos héroes como si fueran personas como uno y eso nos daba una dimensión muy diferente de lo que era una revolución, de lo que era una epopeya. Era como si uno mismo fuera capaz de realizar la epopeya (Rodríguez, 1983).

La canción "A una heroína de la patria" inicia con un piano tímido, todavía en la introducción, donde se logra un desarrollo musical orquestal, principalmente de cuerdas, que evoca dramatismo y heroísmo. El suicidio en la canción, partiendo de sus primeros versos: "Pónganle a la suicida una hoja en la cien / Una siempreviva en el hueco del cuello" se instala desde un lugar mítico, donde el texto poético establece una relación entre la muerte suicida de Haydée y la icónica muerte de Ofelia de Shakespeare en el verso: "Cúbranla con flores como a Ofelia". ${ }^{17}$ El texto musical continúa su desarrollo tomando un progresivo matiz popular, con instrumentos como el bajo eléctrico y la batería, lo que refuerza al texto lírico. Se reitera la idea: "no se queden en su hora inconsolable [...], ríndanle honores como a una valiente que perdió sólo su última batalla”, siendo ésta la muerte.

Dentro de las relaciones que podemos establecer entre Sara González y lo femenino desde un discurso reivindicatorio, por último, señalamos la canción "Qué dice usted" (1977). Aquí, González propone una reflexión desde la igualdad del género femenino, cuya perspectiva es la del feminismo de la igualdad, pues, considera que su canción "es una pregunta a los ojos machistas que todavía nos quedan por allá, que no piensan que una mujer puede hacer todo igual que un hombre y ayudar con eso a la sociedad" (González, s/f).

No hemos abordado en este análisis la condición lésbica de Sara González, pues se trata de un ámbito lo suficientemente importante como para profundizar y problematizar aspectos relacionados con el modo en que sostuvo su propuesta artístico/musical, cuyo asunto ha sido tratado por algunos autores (López, 2008; Hernández, 2015).

\footnotetext{
${ }^{17}$ La muerte de Ofelia se produce tras caer desde un árbol al agua, sufriendo una muerte por ahogo, sin embargo, las circunstancias del personaje respecto de una relación manipuladora entre ella y varios personajes masculinos (el rey, su hermano, su padre y Hamlet) ver: Figueroa, (2015), se transforman en un antecedente de su locura y triste final, por lo que su muerte suicida es descrita como un solitario acto lírico, Cf. Rodríguez (2018).
} 
Resulta interesante destacar que para un futuro análisis sobre este tema se requerirá un enfoque teórico queer, con el fin de dar cuenta de los múltiples elementos y cruces relacionados con la construcción de significados, modos de performatividades, legitimación artística y agenciamiento, bajo un modo de ser de homosexual en el que se producen enunciados que evidencian relaciones de sentido (Deleuze y Guattari, 2002) bajo una lógica que podría invocar un otro decir musical en el espacio artístico de la Nueva Trova Cubana.

\section{Apreciaciones finales}

La figura de la mujer en las canciones de Silvio Rodríguez es imaginada y representada como un objeto simbólico de lo femenino fijo e idealizado desde de los códigos heteronormativos, pero dentro de ese marco fijo, es representada de diferentes formas, pues adquiere múltiples significaciones. A pesar de ello, es posible notar que en la mayoría de las canciones se produce un diálogo binario que transita entre dos espacios: lo político y el amor, habitualmente desde la lírica en un plano metafórico.

La noción de Hombre nuevo en la Revolución Cubana de 1959, no hace ningún tipo de alcance a la tensión entre lo masculino y lo femenino, cuestión que ha sido criticada por los feminismos y considerada como un problema, sobre todo en lo que refiere a la posición de subalternidad que se le ha asignado históricamente a la mujer, a partir de las bases político-económicas que se encuentran en el pensamiento ilustrado y que se comprenden bajo los fundamentos del patriarcado. Por lo tanto, la categoría Hombre nuevo que aparece en el marco de la Revolución Cubana, como ese Hombre viejo, hace eco de un discurso acrítico y ahistórico, haciendo calzar perfectamente sus postulados masculinos y masculinizantes en el espacio social cubano, extendiendo dichos postulados al contexto femenino.

La interpretación de las canciones de Silvio Rodríguez que hace Sara González, podría ser leída como un gesto de valoración hacia la figura del trovador, operando éste como un referente canónico en un espacio de legitimación artística, pero al mismo tiempo, estas interpretaciones se dan dentro de un contexto en el que ambos se relacionan como compañeros músicos en un marco de igualdad artística.

Para Sara González, la mujer es una figura que impulsa permanentemente su propuesta artística desde el reconocimiento patriótico de mujeres como Haydeé Santamaría, como también desde el reconocimiento en la 
formación musical que recibe de Leopoldina Núñez. Pero además, las diferentes mujeres que homenajea en su condición de músicas son objeto de valorización y visibilización.

Si bien la noción de Mujer nueva, se enmarca dentro de un pensamiento socialista, en el caso de Cuba no se advierte una relación con este ideario en todos los aspectos analizados. Es así como la figura de la mujer en el contexto revolucionario es compleja, pues, al mismo tiempo en que se intenta reivindicar mediante una integración mayor en lugares asumidos como masculinos, como también se intenta legislar a favor de la mujer para lograr más espacios de desarrollo en la sociedad, la idealización femenina que se plasma en gran parte de la creación musical de Silvio Rodríguez, junto con el concepto del Hombre nuevo en el contexto revolucionario, no permiten establecer diálogos fluidos con la mujer como figura autónoma.

Pero por otro lado, Sara González reúne esfuerzos para lograr proyectar desde su creación musical a la nueva mujer, posicionándose como una líder artística, que con esta acción, legitima la figura de la trovadora como autora y artífice de un pensamiento político nutrido desde lo revolucionario, con énfasis en la reivindicación de lo femenino, tanto desde la creación artística como desde la acción política. 


\section{Bibliografía}

» Alario, M. (1995). La mujer creada. Lo femenino en el arte occidental. Arte, Individuo y Sociedad, 7, 45-51.

» Alsina, P. (1997). La música y su evolución. Historia de la música con propuestas didácticas y 49 audiciones. Barcelona: Graó.

»Butler, J. (2007). El género en disputa. El feminismo y la subversión de la identidad. Barcelona: Paidós.

»Caballero, J. (2002). La mujer en el imaginario surreal. Figuras femeninas en el universo de André Breton. Castelló de la Plana: Publicaciones de la Universidad de Jaume I.

»Casaus, V. y Nogueras, L. (2002). Que levante la mano la guitarra limpia, La Habana: La memoria.

»Comité Estatal de Trabajo y Seguridad. (1977). Ley de Protección e Higiene del Trabajo Decreto № 101/ Ley № 13. Capítulo XII. Del Trabajo de las Mujeres (pp. 8-10). Recuperado de http://www.aclifim.sld.cu/Leyes/ Decreto101-82.pdf

»Daza, B. (2017). “Óleo de mujer con sombrero. Cuando Silvio interpretó a Marc Chagall". Culto: La tercera, 30/10. Recuperado de http://culto. latercera.com/2017/10/30/oleo-mujer-sombrero-cuando-silvio-rodriguezinterpreto-a-marc-chagall/

»Deleuze, G., y Guattari, F. (2002). Mil mesetas. Capitalismo y esquizofrenia. Valencia: Pre-textos.

»Figueroa, G. (2015). El camino a la locura: Ofelia en el arte de Shakespeare. Revista Chilena Neuro-Psiquiatría, 53(2), 196-204.

» Fubini, E. (2005). La estética musical desde la antigüedad hasta el siglo XX. Madrid: Alianza Editorial.

» González, S. (2009). Canto de mujeres con Sara González. Radio Rebelde, 08 de agosto. Recuperado de http://www.radiorebelde.cu/noticias/cultural/ cultural2-080809.html

» González, S. (2011). Sara también carga contra Pablo Milanés. En S. Rodríguez [Blog Oficial]. Recuperado de http://silviorodriguez.blogspot. com/2011/11/sara-gonzalez-tambien-carga-contra.html

» González, S. (2012). Entrevista a Sara González. Programa de televisión "Con dos que se quieran", conducido por Amaury Pérez. La Habana: ICAIC. Recuperado de https://www.youtube.com/watch?v=tJM0D7RpjI8\&t=140s

» González, S. (S/f). ¿Qué dice usted? [video]. Recuperado de https://www. youtube.com/watch?v=lknzgC1UCiU

» Graper, J. (2014). ¿Qué dice usted?: Discourses of feminity in Nueva Trova Cubana, thesis Master of Arts, School of Music and Dance and the Graduate 
School, University of Oregon, Oregon, United States. Recuperado de https:// scholarsbank.uoregon.edu/xmlui/handle/1794/18411

» Guerrero, C., y Vuskovic, A. (2015). Mimbre (1957). Sergio Bravo, Violeta Parra y los orígenes entrecruzados del Nuevo cine y la Nueva canción, avance de proyecto de investigación La música en el Nuevo cine chileno, Fondo de Fomento Audiovisual, Chile, pp. 1-26. Recuperado de https:// www.academia.edu/22608384/Mimbre_1957__Sergio_Bravo_Violeta_ Parra_y_los_or\%C3\%ADgenes_entrecruzados_del_Nuevo_Cine_y_la_Nueva_ Canci\%C3\%B3n_1

» Guevara, E. (1979). El socialismo y el hombre en Cuba. En J. Aricó (Ed.), El socialismo y el hombre nuevo (pp. 3-17). México: Siglo XXI.

»Hernández, B. (1976). "Sobre la canción política” [Documental], La Habana: ICAIC. Recuperado de https://www.youtube.com/watch?v=G4aNVtpT2es

"Hernández, Y. (2015). Amar la semejanza de su yo: itinerario lésbico neo-trovadoresco. El Caimán Barbudo. Revista Cultural de la Juventud Cubana, 21 de mayo. Recuperado de http://www.caimanbarbudo.cu/ articulos/2015/05/itinerario-lesbico-neotrovadoresco/

»Kollontái, A. (2000 [1977]). La mujer nueva y la nueva moral sexual. México: Juan Pablos Editor.

»Kollontái, A. (2016). La mujer y la lucha de clases. Barcelona: El viejo tropo/ Ediciones de Intervención Cultural SL.

» López, A. (2008). Amores semejantes detrás de las guitarras, La Jiribilla. Revista de Cultura Cubana, 6. Recuperado de http://www.lajiribilla. co.cu/2008/n368_05/368_08.html

» Ministerio de Justicia de Cuba. (1974). Ley de la Maternidad, Decreto Ley № 339. Gaceta Oficial № 7, 115-145, Extraordinaria, 10 de febrero, 2017. Recuperado de https://oig.cepal.org/sites/default/files/cuba_decreto_ ley_339_y_340_de_2017_0.pdf

» Ministerio de Justicia de Cuba. (1975). Código de la Familia, Ley № 1289. Gaceta Oficial, 1-44. Recuperado de https://www.gacetaoficial.gob.cu/html/ codigo\%20de\%20lafamilia.html\#TP

»Montesinos, R. (2002). Las rutas de la masculinidad. Ensayos sobre el cambio cultural en el mundo moderno. Barcelona: Gedisa.

" Moore, A. (2012). Song Means: Analysing and Interpreting Recorded Popular Song. Surrey: Ashgate Publishing Limited.

» Pérez, A. (2012). Entrevista a Sara González. Programa de televisión "Con dos que se quieran". La Habana: ICAIC. Recuperado de https://www.youtube. com/watch?v=tJM0D7RpjI8\&t=140s

»Peris, J. (2011). Cuando digo futuro. Imaginario del desarrollo, cultura y antiintelectualismo en Cuba. Quaderns de Filología, 78, 249-283. Recuperado de http://hdl.handle.net/10550/58099

»Perrot, M. (1989). La mujer en el discurso del siglo XIX. En Mujeres y 
hombres en la formación del pensamiento occidental. Actas de las VII Jornadas de Investigación Interdisciplinaria sobre la mujer (pp. 115-128). Madrid: Universidad Autónoma de Madrid.

»Ramos, D. (1989). La mujer sujeto creador y objeto de creación en el discurso literario. En Mujeres y hombres en la formación del pensamiento occidental. Actas de las VII Jornadas de Investigación Interdisciplinaria sobre la mujer (pp. 229-246). Madrid: Universidad Autónoma de Madrid.

»Randall, M. (2015). Haydeé Santamaría. Cuban Revolutionary: She Led by Transgression. Duke: University Press.

» Rodríguez, M. (2018). ¿Ser o no ser Ofelia? El rol femenino en Hamlet desde su desenvolvimiento dramático y social. Alpha, 46, 251-261.

» Rodríguez, S. (1976). Sobre la canción política. En B. Hernández (dir.). Documental. La Habana: ICAIC. Recuperado de https://www.youtube.com/ watch?v=G4aNVtpT2es

»Rodríguez, S. (1983). Que levante la mano la guitarra. En P. Casaus. Documental. La Habana: ICAIC. Recuperado de https://www.youtube.com/ watch?v=VWrB45cKpQY

»Rodríguez, S. (1992). Por quien merece amor. En A. Figueredo. Documental. La Habana: Trimagen. Recuperado de https://www.youtube.com/ watch?v=lwOQbjI4DBw\&t=2830s

» Rodríguez, S. (2000). Estado de gracia. En L. De los Santos. Documental. La Habana: ICAIC, en colaboración con Estudios Ojalá, TV Serrana y EICTV.

» Rodríguez, S. (2013). Comentario de Silvio Rodríguez. En Segunda cita. Blog en evolución y Red abeja. Recuperado de https://segundacita.blogspot. com/2013/04/exposicion-de-mujer-con-sombrero.html visitado el $04 / 03 / 2019$

» Rodríguez, S. (2017). Cuba. Entrevista a Silvio Rodríguez: Mis canciones son mis aspiraciones. En R. Fernández (dir.). Recuperado de http://www. resumenlatinoamericano.org/2017/03/25/cultura-entrevista-a-silviorodriguez-mis-canciones-son-mis-aspiraciones-videos/

》 Rodríguez, S. (s/f.) Hoy mi deber era. [Explicación de la canción, video publicado 10/10/2016]. Recuperado de https://www.youtube.com/ watch?v=mJb7HsXUooM

» Rojas, P. (2017). La idea de hombre nuevo en "El hombre" de Rolando Alarcón, ponencia presentada en el III Congreso de musicología de la Asociación Regional de América Latina y el Caribe, ARLAC/IMS, Santos. Inédito.

»Santa Biblia. (2012). La epístola del Apóstol San Pablo a los Efesios y La epístola del Apóstol San Pablo a los Colosenses [Versión Reina Valera-Gómez] (pp. 255-263 y pp. 269-273). Hoplic Publishing Co.

»Tin, L.-G. (2012). La invención de la cultura heterosexual. Buenos Aires: El cuento de plata. 
»Vidaurrázaga, T. (2012). “¿El hombre nuevo?: moral revolucionaria guevarista y militancia femenina. El caso del MIR", Revista NOMADÍAS, 15, 69-89.

\section{Discografía}

» Fernández, T. (2007 [1968]). Teresita canta a Martí, [A guitarra limpia]. La Habana: Centro Pablo. Recuperado de https://www.youtube.com/watch?v= 6iW1hQBdcT0\&list=OLAK5uy_lVIV5Lh0fRDZRK0H9ahY0euJjtpNDvA_4

» González, S. (1975). Versos José Martí. Cantados por Sara González [LP]. La Habana: EGREM. Recuperado de https://perrerac.org/cuba/sara-gonzlezversos-jos-mart-cantados-por-sara-gonzlez-1975/1825/

» González, S., y García, F. (2011 [1982]). A una heroína de la Patria. En Cuatro cosas. La Habana: EGREM. Recuperado de https://open.spotify.com/ track/3qACkov8AVfOR5TjjwZK5n

» González, S. (1998). Querer tener riendas sueltas [CD]. En Mírame. Madrid: CRIN-Creativos.

»González, S. (2003). Ausencia. En Cantos de mujer [CD]. La Habana: Altafonte.

" González, S. (2009). Cantos de mujer, Vol. II [CD]. La Habana: Bis Music.

» Hevia, M.-L. (1999). Ausencia. En Del verso a la mar [CD]. La Habana: Bis Music.

» Rodríguez, S. (1994 [1977]). Cuando digo futuro. En Silvio Rodríguez. Cuando digo futuro, [CD]. Madrid: Fonomusic.

» Rodríguez, S. (1994 [1972]). Canción de la nueva escuela. En Silvio Rodríguez. Cuando digo futuro [CD]. Madrid: Fonomusic.

» Rodríguez, S. (1994 [1982]). Hoy mi deber era. En Unicornio [CD]. Madrid: Fonomusic.

»Rodríguez, S. (1982 [1980]). Con diez años de menos. En Rabo de nube, [Casete]. Santiago de Chile: Alerce.

\section{Biografía / Biografia / Biography}

\section{Lorena Alejandra Valdebenito Carrasco}

Doctora en Musicología por la Universidad de Salamanca, España. Se ha desempeñando como académica en diferentes instituciones educativas. Es parte del comité editorial de Neuma, Revista de Música y Docencia Musical de la Universidad de Talca, y editora de Contrapulso, Revista Latinoamericana de Estudios en Música Popular del Instituto de Música de la Universidad Alberto Hurtado. Es miembro del Comité Editorial Área de Música de Ediciones Universidad Alberto Hurtado de la Universidad Alberto Hurtado. También es miembro de la Asociación Chilena de Musicología y 
del colectivo internacional Música y Género. Grupo de Estudios Latinoamericanos. Se ha desempeñado durante varios años como evaluadora en diversas líneas del Fondo de la Música del Ministerio de las Culturas y las Artes. Ha sido evaluadora en procesos de acreditación académica a nivel de posgrado para el Consejo Nacional de Acreditación. Actualmente es directora de la carrera de Pedagogía en Música del Instituto de Música de la Universidad Alberto Hurtado y académica en el Magíster en Musicología Latinoamericana de la misma Universidad. Sus líneas de investigación son: las representaciones y los discursos en torno a la formación de sujetos en la música, y los estudios sobre música y género, la construcción de feminidades y masculinidades en las músicas populares. 